\title{
THE USE OF SOCIAL THEORIES IN 20 YEARS OF WG 8.2 EMPIRICAL RESEARCH
}

\author{
Donal Flynn \\ University of Manchester Institute of \\ Science and Technology \\ Peggy Gregory \\ University of Central Lancashire
}

\begin{abstract}
We study the use of social theories in empirical Information Systems research in the IFIP WG 8.2 conference proceedings since the 1984 Manchester conference. Our results are that interpretivist research and the use of qualitative methods have increased significantly and that only 22 percent of included papers generate theory or concepts according to a narrow definition of theory based on Walsham's classification; the majority of WG 8.2 researchers thus appear reluctant to generalize to theory from their findings, particularly when undertaking interpretivist research. However, using a wide definition of theory that includes researchers' own theory used in their papers, we suggest that additional theory is in fact being generated although in a non-explicit manner. We close by pointing out the benefits of theory generation, inviting WG 8.2 researchers to make their use of theory more explicit and to familiarize themselves with the view that there are forms of generality which are possible within the interpretivist paradigm.
\end{abstract}

Keywords: Interpretivist research, social theory, generalization, empirical research

\section{INTRODUCTION}

We discuss trends in the relationship between social theory and empirical research in the papers published by the WG 8.2 community since 1984 . The use of theory and its relationship to empirical research in Information Systems has come under increasing attention recently, particularly with regard to research results. Hirschheim and Klein 
(2000) state that we need more generalization in our research, and call for papers on historical analysis to build cumulative knowledge and to learn from previous research. Sawyer (2000) discusses the lack of theory development in organizational computing infrastructures and, in Sawyer and Chen (2002), states that there is "almost no proof of concept research in the 8.2 literature." Klein (1999) and Klein and Huynh (1999) point to a lack of theory in interpretive IS research results; they criticize thick descriptions as they "tend to be rather verbose and make it difficult to form a global picture of the social phenomena being researched" (Klein and Huynh 1999, p. 79).

There has undoubtedly been a strong tendency to question the appropriateness, within an intensive research paradigm, of what is often perceived as formal theory (Van Maanen 1995). However, writers such as Silverman (2000) and Eisenhardt (1989) emphasize the ways in which theory may make a contribution within intensive research. In addition, recent articles have appeared that deconstruct the concept of generalizability, pointing out to IS researchers that in fact there are forms of "generality" with which they can feel comfortable, and they need no longer criticize their research for lacking generalizability (Baskerville and Lee 1999). We were thus interested in investigating the extent to which 8.2 researchers were engaged in theory development, and in generalization in particular, from their empirical research.

If theory development can be considered as output from the research process, then we were also interested in theory as input. We wanted to investigate questions such as were social theories being used by 8.2 researchers (or were studies purely inductive)? Which social theories were being used and were they by famous or by little-known social theorists? How was theory being used (that is, deductively or as sensitizing theory)? Did studies use qualitative, quantitative, or mixed data? Were researchers building on theory and was that theory their own or that of others? To some extent, this part of our investigation was inspired by Jones (2000); however, we went one step further and, rather than regarding citations as an indicator of use of social theory, we wanted to look at those social theories that were deeply integrated into the work of IS researchers. We describe our method in section 2, including selection and validity criteria and the categories used for paper classification, discuss results in section 3 , and conclude with a discussion and our conclusions in section 4 .

\section{METHOD}

\subsection{Selection Criteria}

Our base for data generation was the published IFIP WG.2 conference proceedings since 1984; these are shown in Table 1. Of the 381 papers published in the 17 conference proceedings between 1984 and 2003,175 papers were included in the study. Keynotes were considered for inclusion but panels were not considered. The criteria for including a paper were that (1) it reported the conduct of empirical research and (2) social theory was central to the empirical work, either as input, output, or both. In all but a few cases (five or less) we did not find it difficult to agree on the selection of papers for inclusion, as papers which report on empirical work also deal with some sort of social theory when discussing their results. Papers excluded by these criteria were 
Table 1. IFIP WG 8.2 Conferences: 1984-2003. (Adapted and extended from Table 1 in M. Jones, "The Moving Finger: The Use of Social Theory in WG 8.2 Conference Papers, 19751999," in R. Baskerville, J. Stage, and J. I. DeGross (Eds.), Organizational and Social Perspectives on Information Technology, Boston: Kluwer, 2000, pp. 15-31.)

\begin{tabular}{|lll|}
\hline Date & Published Proceedings & Location \\
\hline September 1984 & Mumford et al. (1985) & Manchester, UK \\
August 1986 & Bjørn- Andersen and Davis (1988) & Noordwijkerhout, NL \\
May 1987 & Klein and Kumar (1989) & Atlanta, GA, USA \\
July 1989 & Kaiser and Oppeland (1990) & Ithaca, NY, USA \\
December 1990 & Nissen, Klein and Hirschheim (1991) & Copenhagen, DK \\
June 1992 & Kendall, Lyytinen and DeGross (1992) & Minneapolis, MN, USA \\
May 1993 & Avison, Kendall, and DeGross (1993) & Noordwijkerhout, NL \\
August 1994 & Baskerville et al. (1994) & Ann Arbor, MI, USA \\
December 1995 & Orlikowski et al. (1996) & Cambridge, UK \\
August 1996 & Brinkkemper, Lyytinen and Welke (1996) & Atlanta, GA, USA \\
May- June 1997 & Lee, Liebenau and DeGross (1997) & Philadelphia, PA, USA \\
December 1998 & Larsen, Levine and DeGross (1998) & Helsinki, Finland \\
August 1999 & Ngwenyama et al. (1999) & St. Louis, MO, USA \\
June 2000 & Baskerville, Stage and DeGross (2000) & Aalborg, Denmark \\
July 2001 & Russo, Fitzgerald and DeGross (2001) & Boise, ID, USA \\
December 2002 & Wynn et al. (2002) & Barcelona, Spain \\
June 2003 & Korpela, Montealegre and Poulymenakou & Athens, Greece \\
& (2003) & \\
\hline
\end{tabular}

literature surveys, thought experiments, and those which exclusively examined texts (less than five); we additionally excluded papers whose focus was research methodology (the great majority of these were theoretical only). Generally the empirical work being reported was undertaken by the paper's authors; however, a few cases were found in which the primary research work was either not undertaken by the authors, or had been completed previously and was being reinterpreted. In these cases, as long as the interpretation or description of the empirical work was a primary feature of the paper it was included. Our definition of social theory was

\section{A theory, model, framework, or set of concepts or insights concerning \\ - social cognition (e.g.. attitudes, values, beliefs) \\ - social behavior (e.g., events, actions taken, structure interacting with action)}

We did not find difficulty in applying this definition as it quickly became obvious that all our included empirical papers dealt with social theory! This is hardly surprising as WG 8.2 focuses on the interaction between IS and the social context. Although we considered formulating a narrower definition, we gave this up not only on the grounds 
of subjectivity, but also because we wanted to gain an overall picture of social theory use.

\subsection{Validity}

We approached the need for data validity by initially agreeing on inclusion criteria as well as the categories and their values for paper classification. We read all papers independently and then compared each others' inclusions and categorizations with our own. Where there were differences, they were resolved in early meetings by combining category values (such as case study and ethnography) and in later meetings by revising category definitions, rereading papers, discussion and reaching agreement.

\subsection{Paper Classification}

We now discuss the categories, and their associated subcategories, that we used to classify each paper and the degree ofdiscussion we required to reach agreement on their meaning and application. We became aware that there were different degrees of subjectivity associated with each of the categories, and that other researchers, with different perspectives to ours, would have classified some papers differently. We defined some subcategories as combinations of other subcategories (for example, field study/survey) and others to be exclusive. Exclusive subcategories occur either as a result of the data (for example, male or female) or where we have decided that a subcategory represents a primary focus. Appendix A details our categorizations for all of the papers.

Research Paradigm. This category is based on the ISWorld description of philosophical perspectives underlying qualitative research (Myers 2004), that identifies three main paradigms: interpretivist, positivist, and critical. However, our interpretation of the positivist paradigm differs, as we decided not to consider theory testing to be a component of this paradigm. The reason for this is that we found that there were many papers that tested theory in an informal way but were interpretivist, in the sense that they were based on an ontological view that reality was socially constructed by peoples' meanings (including those of the researcher), together with a matching epistemology. We decided, therefore, to decouple theory testing from positivism and to regard it in a separate category, discussed below, concerning the relationship of input theory to the research. We took the view that a paper could be based on only one paradigm. There were less than 10 papers where we initially disagreed; this was because the paradigms of those papers were difficult to infer from the information presented.

Research Data. This is based on the three types described in Myers (2004): qualitative data (including data resulting from interviews, documents, questionnaires, participant observation, and researchers' impressions and reactions); quantitative data (data consisting of numbers, with the use ofnumerical or statistical means to manipulate them in data analysis); mixed qualitative and quantitative data. There were less than five papers where we initially disagreed, mainly on whether a paper was mixed or quantitative.

Research Method. Myers considers (1) qualitative research methods (action research, case study research, ethnography, grounded theory) and quantitative research 
methods (survey, lab experiment, formal methods, numerical methods). We omitted grounded theory, as it seemed to be more about the relationship of input theory to research (see below). We also found that the distinction between case study and ethnography was not easy to make, as ethnography is characterized by the fact that the researcher "spends a significant amount of time in the field" (Myers 2004). As this information was rarely available from the papers, and as only three papers explicitly claimed to be using ethnographic research, we decided to combine these two methods into one that we termed field study. For quantitative methods, Myers doesn't mention field experiments, so we added these in with lab experiments, using the term experiment. We regarded a survey as exclusively collecting data by phone, e-mail, post, or automatic tracing of interaction with the computer. Our final list was action research, field study, survey, experiment, formal methods, numerical methods, and combinations of these methods. There were only a few papers where we initially disagreed, mainly on the combination of methods that papers used. We considered classifying a paper as action research only if the authors stated they were using this method.

Level of social focus. Based on Walsham's (2000) five levels, we added a global level and classified each paper according to six categories that represented the granularity of social focus: (1) personal, (2) group, (3) organization, (4) interorganization, (5) society, and (6) global. Some papers involved more than one level; in these cases, we assigned a primary level of focus to the paper, as well as recording all levels. For perhaps 25 percent of papers, classification required some discussion to reach agreement, involving writing down definitions for each of the levels.

Input theory. Papers were analyzed in terms of the relationship between input theory and their research. Three categories were identified: (1) deductive, (2) sensitizing, and (3) inductive (Bryman 2001). Deductive papers are where a theory is proposed at the beginning and then tested by evidence. Sensitizing papers use theory to organize the empirical research but do not overtly test theory. In inductive papers, empirical phenomena are observed first and inferences drawn from them. Inductive papers almost invariably state that they are adopting this approach with the intention of avoiding prejudgment of the data to be generated. Although these are ideal categories, occupying positions on a spectrum (Sawyer 2000), and although much research is iterative or abductive (Alvesson and Skoldberg 2000), in most cases we categorized the papers by following the main emphasis set by authors. There was some initial disagreement between us, for perhaps 15 percent of papers, mainly concerning whether a paper was deductive or sensitizing; we resolved this by re-reading the paper and reaching agreement.

Own/other theory. The input theory of papers could originate from either (1) the author(s) themselves or (2) others. The first type of paper used a theory generated by the author(s), usually based on the literature or, much more infrequently, on results from previous research by the author(s). The second type used the theory of other authors without modification. There were less than five papers where we initially disagreed on this category.

Output theory. Walsham's (1995) four types of analytic generalization were used to investigate the type of output theory generated by the papers. The types are (1) development of theory, (2) generation of concepts, (3) drawing of specific implications, and (4) contribution of rich insights. Where authors used text only for 
discussion of their findings, and did not use the term concept in their discussion, we (perhaps rather crudely) classified their results as rich insights or specific implications. Where they appeared to be abstracting their results for possible use in contexts other than those presented in the paper, we considered these to be concepts. We are aware that this classification is subjective, but typically, authors were explicit about the fact that they intended to generate a theory. If they had a diagram which appeared to contain concepts shown in relationship to one another, we considered this to be a theory. There were about 10 percent of papers where we initially disagreed on this category.

ISR category. Orlikowski and Iacono (2001) discuss five metacategories of ITcomputational, ensemble, nominal, proxy, and tool—based on assumptions about and treatments of IT as an artifact in IS research. We thought that this category would help us relate our results to the wider IS community. This category caused us the most disagreement, concerning interpretation of the meaning and application of the metacategories, as Orlikowski and Iacono do not present the detail of their categorizations of the 10 years of Information Systems research papers they studied. There were about 30 percent of papers where we initially disagreed, and we wrote definitions and application guidance for each metacategory.

Region. We classified papers by the region of the first author, based on the affiliation details given in the papers. The regions are Africa, Asia, Australasia (Australia and New Zealand), North America, South America, and Europe.

Gender. We classified papers by the gender (male or female) of the first author based on the details given in the papers.

\section{RESULTS}

\subsection{Social Theory Papers}

Table 2 gives details of the number of included papers (empirical social theory papers) found in each conference. There was only one conference (1984) in which there were no papers that met our criteria. As the theme of this conference was research methods, it is unsurprising that the papers concentrated on theoretical issues rather than the results of empirical studies.

Looking at the data in terms of included empirical social theory papers as a percentage of the total number of papers per year, the high points were in 1994 and 2003 and the low points were in 1984 and 1996. The trend shown by the data is for a gradual increase in the percentage of papers from 1984 to 1994 (with a couple of dips on the way in 1987 and 1990), followed by a sharp decrease between 1995 and 1996, followed by another gradual increase from 1996 to 2003 . We conjecture that the dip in the mid-1990s reflects the dichotomy in WG 8.2 between research into IT artifacts and research into social issues, as exemplified by the 1996 method engineering joint WG 8.1/8.2 conference.

We summarize our categorization results in the following sections, mainly in tables but using graphs to indicate interesting trends. 
Table 2. Numbers of Papers by Conference

\begin{tabular}{|ccccc|}
\hline Conference & WG(s) & $\begin{array}{c}\text { Total number } \\
\text { papers }\end{array}$ & $\begin{array}{c}\text { Empirical Social } \\
\text { theory papers }\end{array}$ & Percent of total \\
\hline 1984 & 8.2 & 17 & 0 & $0 \%$ \\
1986 & 8.2 & 21 & 7 & $33 \%$ \\
1987 & 8.2 & 15 & 4 & $27 \%$ \\
1989 & 8.2 & 21 & 13 & $62 \%$ \\
1990 & 8.2 & 30 & 8 & $27 \%$ \\
1992 & 8.2 & 17 & 9 & $53 \%$ \\
1993 & 8.2 & 24 & 15 & $63 \%$ \\
1994 & 8.2 & 20 & 15 & $75 \%$ \\
1995 & 8.2 & 21 & 12 & $57 \%$ \\
1996 & $8.1 / 8.2$ & 19 & 3 & $16 \%$ \\
1997 & 8.2 & 24 & 6 & $25 \%$ \\
1998 & $8.2 / 8.6$ & 31 & 19 & $61 \%$ \\
1999 & 8.2 & 16 & 6 & $38 \%$ \\
2000 & 8.2 & 27 & 10 & $37 \%$ \\
2001 & 8.2 & 28 & 14 & $50 \%$ \\
2002 & 8.2 & 23 & 13 & $57 \%$ \\
2003 & $8.2 / 9.4$ & 27 & 21 & $78 \%$ \\
Total & & 381 & 175 & $46 \%$ \\
\hline
\end{tabular}

\subsection{Research Paradigm, Research Data, and Research Method}

The papers were first analyzed for their research paradigm, the research data gathered, and the research method used. Table 3 shows a summary of the results for five of the categories we used. The table shows results as a percentage of the included papers in any one year (not as a percentage of all papers).

A clear trend was visible in the data concerning research paradigms, as shown in Figure 1. Over the years the interpretivist paradigm has been the most commonly adopted, with the exception of 1989 in which there were more positivist papers than interpretivist, and the relative number of positivist papers has diminished. In the late 1980s and early 1990s, the mix of positivist and interpretivist papers was fairly even, whereas over the last decade the research emphasis has been far more clearly on the interpretivist side. Only a very small (1 percent) proportion of papers adopt the critical paradigm.

Looking at the research data categories shown in Table 3 there has been a gradual increase in the use of qualitative data over the last 20 years. The number of papers using qualitative data has exceeded all other types of data since 1996, with a marked increase in the percentage of papers using purely qualitative data since 1997. In contrast, during the early period from 1984 until the mid-1990s, research data was more mixed, with the use of quantitative data peaking in 1989. Empirical research in WG 8.2 has been moving more clearly toward being interpretivist and qualitative. 




Figure 1. Research in Paradigms

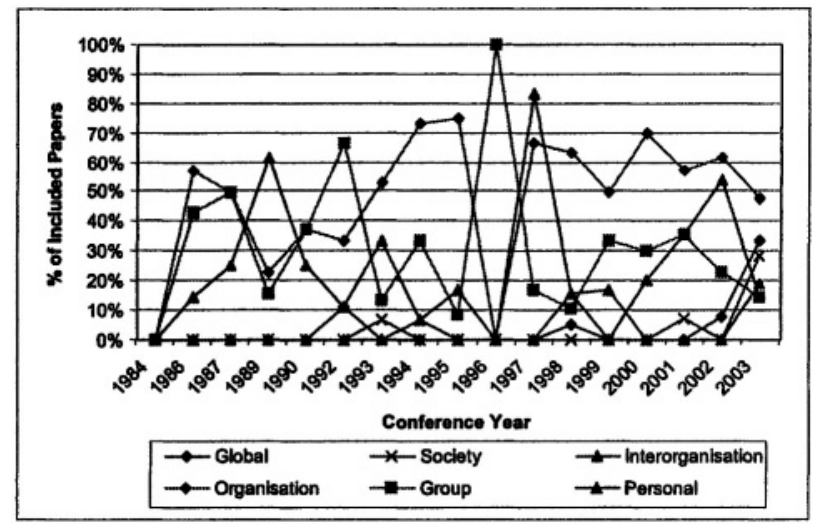

Figure 2. Level of Social Focus

The field study method has been the most widely used research method over all of the years. Surveys and experiments were used more frequently in the late 1980s and early 1990s. Only two papers used numerical methods.

\subsection{Level of Social Focus and Conceptualizations of the IT Artifact}

Looking at the level of social focus of the papers over all of the years in Figure 2, and considering papers categorized as having more than one level of focus, 54 percent of the papers focus on the organizational level and 26 percent on the personal level. There were very few papers that focused on the global, societal, or interorganizational levels (about 5 percent for each category); the exception to this was the 2003 conference, the theme of which was "Perspectives and Challenges of Organizational Information 
Table 3. Summary of Paper Analysis Showing Percentages of Papers in Categories, by Year

\begin{tabular}{|c|c|c|c|c|c|c|c|c|c|c|c|c|c|c|c|c|c|c|c|}
\hline 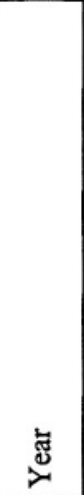 & 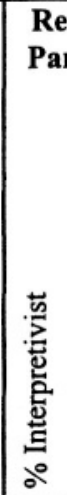 & 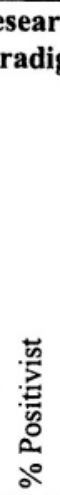 & 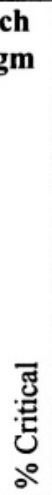 & 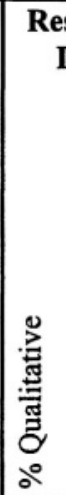 & 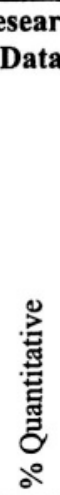 & 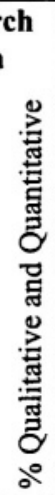 & 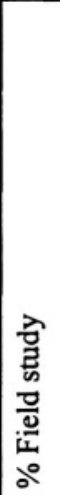 & 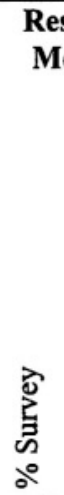 & 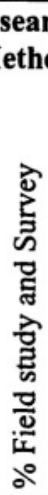 & 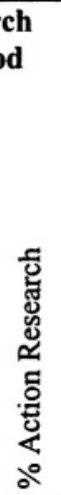 & 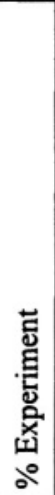 & $\begin{array}{l}\frac{0}{\pi} \\
\sum_{0}^{\circ}\end{array}$ & 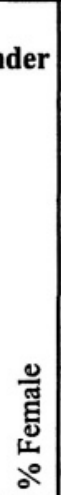 & 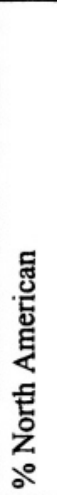 & 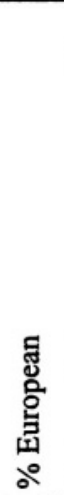 & 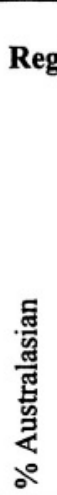 & 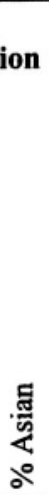 & 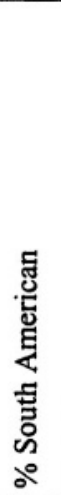 &  \\
\hline 1984 & 0 & 0 & 0 & 0 & 0 & 0 & 0 & 0 & 0 & 0 & $\overline{0}$ & 0 & 0 & 0 & $\overline{0}$ & 0 & 0 & 0 & 0 \\
\hline 86 & 86 & 14 & 0 & 43 & 0 & 57 & 86 & 14 & 1 & 14 & 0 & 86 & 14 & 3 & 57 & 0 & 0 & 0 & 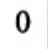 \\
\hline 1987 & 75 & 25 & 0 & 75 & 0 & 25 & 100 & 0 & 0 & 0 & 0 & 75 & 25 & 50 & 50 & 0 & 0 & 0 & 0 \\
\hline 1989 & 31 & 69 & 0 & 15 & 54 & 31 & 54 & 46 & 4 & 0 & 31 & 62 & 38 & 5 & 8 &  & 8 & 0 & . \\
\hline 1990 & 63 & 38 & 0 & 63 & 25 & 13 & 50 & 13 & 0 & 0 & 25 & 63 & 38 & 88 & 0 & 13 & 0 & 0 & 0 \\
\hline 1992 & 56 & 44 & 0 & 4 & 33 & 22 & 56 & 22 & 0 & 11 & 11 & 44 & 56 & 67 & 22 & 1 & 0 & 0 & 0 \\
\hline 1993 & 73 & 27 & 0 & 60 & 20 & 20 & 60 & 33 & 3 & 27 & 0 & 87 & 13 & 13 & 60 & 20 & 0 & 7 & 0 \\
\hline 1994 & 100 & 0 & 0 & 93 & 0 & 7 & 100 & 7 & 1 & 0 & 0 & 60 & 40 & 33 & 60 & 7 & 0 & 0 & 0 \\
\hline 1995 & 92 & 8 & 0 & 75 & 8 & 17 & 83 & 25 & 1 & 0 & 0 & 3 & 17 & 25 & 67 & 0 & 0 & 0 &  \\
\hline 1996 & 67 & 33 & 0 & 33 & 0 & 67 & 100 & 0 & 0 & 0 & 0 & 100 & 0 & 0 & 100 & 0 & 0 & 0 & 0 \\
\hline 1997 & 100 & 0 & 0 & 83 & 0 & 17 & 100 & 0 & 0 & 0 & 0 & 67 & 33 & 33 & 33 & 33 & 0 & 0 & 0 \\
\hline 1998 & 95 & 5 & 0 & 89 & 5 & 5 & 79 & 5 & 0 & 11 & 0 & 58 & 42 & 16 & 74 & 11 & 0 & 0 & 0 \\
\hline 1999 & 100 & 0 & 0 & 100 & 0 & 0 & 100 & 0 & 0 & 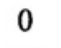 & 0 & 67 & 33 & 33 & 33 & 17 & 0 & 0 & 17 \\
\hline 2000 & 100 & 0 & 0 & 100 & 0 & 0 & 90 & 0 & 0 & 10 & 0 & 20 & 80 & 30 & 70 & 0 & 0 & 0 & 0 \\
\hline 01 & 86 & 14 & 0 & 86 & 14 & 0 & 64 & 14 & 0 & 21 & 0 & 86 & 14 & 29 & 71 & 0 & 0 & 0 & 0 \\
\hline 2002 & 85 & 0 & 15 & 100 & 0 & 0 & 92 & 0 & 0 & 0 & 8 & 54 & 46 & 23 & 69 & 8 & 0 & 0 & 0 \\
\hline 2003 & 95 & 5 & 0 & 76 & 0 & 24 & 95 & 19 & 3 & 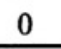 & 0 & 33 & 67 & 14 & 52 & 19 & 5 & 0 & 10 \\
\hline otal & 83 & 16 & 1 & 74 & 11 & 15 & 15 & 7 & 7 & 1 & 2 & 62 & 38 & 34 & 53 & 10 & 1 & 1 & 2 \\
\hline
\end{tabular}

Systems in the Context of Globalization." Given the growing importance of globalization caused by the rapid development of the Internet, this area of research is likely to increase in the future. Empirical studies investigating groups have been represented in each conference over the period, accounting for 26 percent of the total papers.

Results from categorizing the IT focus of the papers, according to the Orlikowski and Iacono (2001) categories for conceptualizing the IT artifact, are shown in Figure 3. Of the papers, 84 percent were in the ensemble category (mostly development and embedded), 10 percent were in the proxy category, 3 percent were in the tool category, 3 percent were in the nominal category, and none were in the computational category. These results are significantly at variance with the review of Sawyer and Chen (2002), who surveyed both Information Systems Research and WG 8.2 papers from 1990 to mid-2001. For the WG 8.2 papers, they found 29 percent were in the ensemble category 


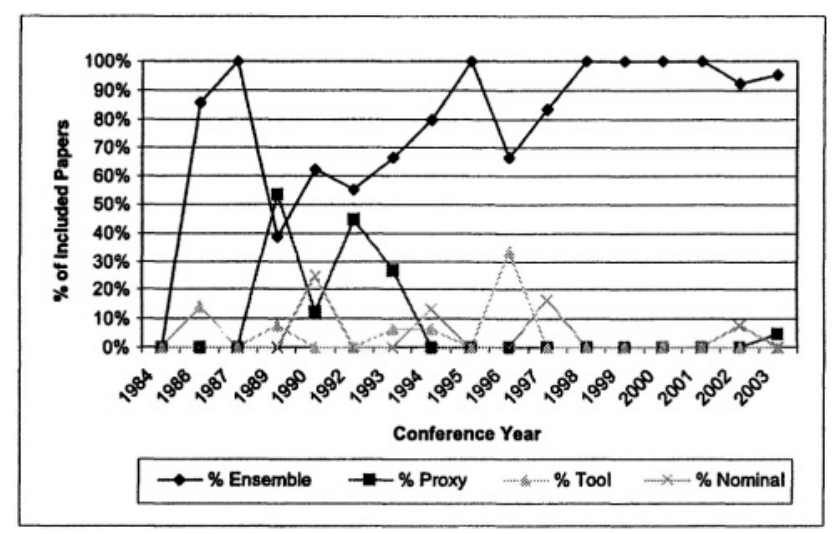

Figure 3. Conceptualizations of the IT Artifact

and 45 percent were in the nominal category. We explain the difference between their results and ours as due to the fact that they included all papers from about 11 years of WG 8.2, in comparison to our inclusion of only empirical papers over a 20-year period. They would, therefore, have included all of the theoretical papers we excluded, many of which might be expected to fall into the nominal category. However, as we had a significant amount of disagreement in our initial categorizations, some of the variance is likely to be explained by differences between interpretations of the categories. This is also suggested by the differences between the results of Sawyer and Chen and by Orlikowski and Iacono on a similar set of Information Systems research papers.

\subsection{Gender and Region}

From Table 3 it can be seen that there were more papers written by male authors than by female with a ratio of 62:38. This is perhaps not surprising as it reflects the fact that more men than women work in academic departments in universities. However, since 2000, the picture has become more balanced. In both 2000 and 2003 there was a higher percentage of women authors than men authors, and in total over the last five conferences since 1999, there were an even number of papers by male and female first authors (32 each).

Most authors come from either North America or Europe. There is a fair degree of correlation between the venue of the conference and the number of authors coming from that region. Since the conferences have been held either in the United States or Europe it is not surprising that these two groups of authors are the most prominent. Out of 17 conferences, 9 have been held in Europe and 8 have been held in the United States. However the data does not exactly follow the venue of the conference. There is another, broader trend that indicates that whereas in the early years up to 1992 the North American authors were more prominent, since 1993 the European authors have been more prominent. The number of authors from Australasia has been fairly steady since 1990. However the numbers of authors from Asia, Africa, and South America has been very low. The 2003 conference, with its global theme, did attract authors from a wider range of regions; we suggest that WG 8.2 widen its global range of conference venues. 




Figure 4. Research Approach: Input Theory Use in Research

\subsection{Input Theory: Manner of Use in Research}

The results in Figure 4 show that while the number of papers using inductive research approaches has remained fairly steady over the last 20 years, the amount of deductive research being undertaken has gradually diminished and the amount of sensitizing research has increased. For the last few years, the numbers of papers using inductive and deductive approaches has been about the same. However, the trends are not well defined, indicating plurality in the research field.

\subsection{Input Theory: Author or Other Source}

Input theory can originate either from the author(s) or from others. Figure 5 shows a yearly shifting emphasis but, since 2001, a higher percentage of authors have used the theory of others for their empirical research.

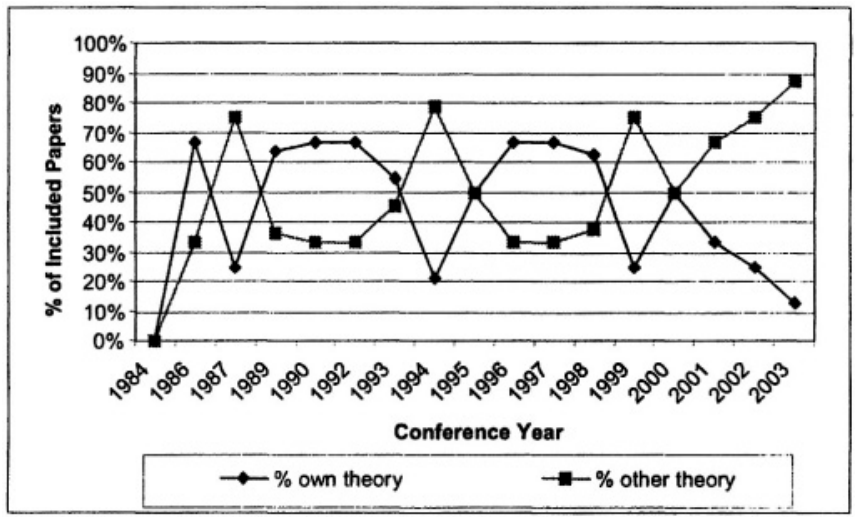

Figure 5. Source of Theory Used 
Table 4. Top 10 Social Theories/Theorists

\begin{tabular}{lc}
\hline \multicolumn{1}{c}{ Social Theory/Social Theorist } & $\begin{array}{c}\text { Number of } \\
\text { papers }\end{array}$ \\
\hline Actor network theory & 9 \\
Structuration theory & 5 \\
Foucault & 4 \\
Kling (Web model) & 3 \\
Orlikowski & 3 \\
Activity theory & 2 \\
Beck (globalization/identity) & 2 \\
Bourdieu & 2 \\
Giddens (globalization/identity) & 2 \\
Star (boundary objects) & 2 \\
\hline
\end{tabular}

Table 4 shows the most frequently used key theories or theorists from the papers. This is a subjective ranking based on our assessment of the key theories and theorists as presented by paper authors. Comparing findings from this survey with Jones' (2000) review of social theorists in WG 8.2 conferences from 1979 through 1999, there are striking similarities between his top 10 list and this one: the actor network theorists, Giddens and Foucault, are still there. Some of the other theorists on Jones's list, such as Burrell and Morgan, Berger, Popper, and Glaser, do not appear because of their focus on research methods. More significantly, the top 10 theories and theorists shown in Table 4 only account for 19 percent of our papers. Therefore, the great majority of papers use less well-known middle range theory, such as Thomas' conflict management model or social presence theory.

\subsection{Output Theory: Theory Development}

Walsham's (1995) four types of analytic generalization were used to investigate the type of theory generated by the research. Only 22 percent of the papers were found to generate theory or develop concepts; the other 78 percent were found to generate specific implications or contribute rich insights. In Table 5, we show percentages of papers generating theory or concepts. We term this classification narrow theory output. We also considered a wider notion of output theory that included all of the papers which had used their own theory as input theory for the empirical work (see section 3.6). The result of this classification is termed wide theory output in Table 5. As can be seen from the table, adopting a wide concept of theory results in a much greater proportion of papers (49 percent) that generate theory as a result of their research. We return to this point later.

\subsection{Generation of Output Theory}

In this section, we investigate the types of papers that generate output theory, i.e., the Walsham (1995) subcategories termed theory and concepts. 
Table 5. Contrasting Narrow and Wide Theory Output

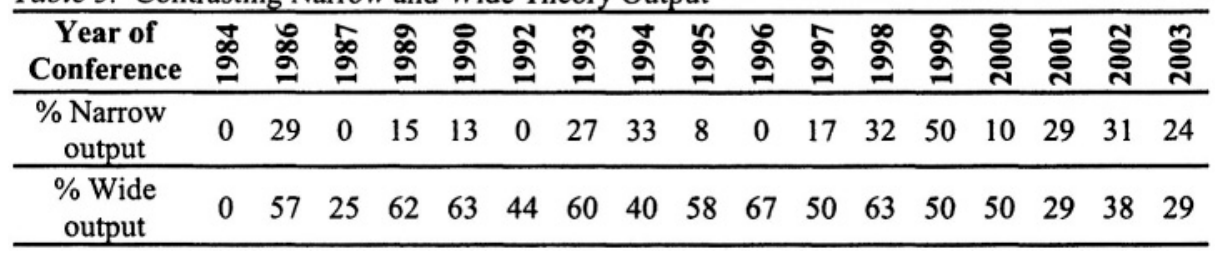

Research paradigm. We used a narrow view of positivist (excluding papers with a deductive use of theory) and a broad view of positivist (including papers with a deductive use of theory). On a narrow view, Table 6 shows that 25 percent of positivist papers generate theory, compared to 23 percent of interpretivist papers. This was a surprising result as we thought that positivist papers would be more likely to generate theory. As over two-thirds of the interpretivist papers that generate theory are from the last six years, we conclude that there is a trend in interpretivist papers toward theory generation. From a broad view of positivist, 36 percent of positivist papers, compared to only 18 percent of interpretivist (excluding deductive) papers, generate theory, which is a more traditional result.

Research Data. We found that there was little difference (24 percent qualitative, 21 percent quantitative, 19 percent mixed) between types of papers that generated theory. This was surprising as we thought that quantitative papers would be more likely to generate theory.

Research Method. We found that field studies (24 percent) and experiments (25 percent) generate the most theory. In all, 15 percent of survey papers generate theory. This was surprising as we thought that harder methods would be more likely to generate theory. Again, we found it surprising that only 17 percent of action research papers generate theory as one of its hallmarks, differentiating it from consultancy, is held to be its emphasis on the refinement of initial theory (Baskerville and Wood-Harper 1996).

\subsection{Gender of First Author}

This section investigates the relationship between first author gender and different categories of papers, shown in Tables 7, 8 and 9 .

Research paradigm. Male-authored papers adopt a positivist paradigm slightly more than female-authored papers. Using a narrow view of positivist, 18 percent of male-authored papers adopt this paradigm compared to 13 percent of female-authored papers. Using a broad view of positivist, the difference is more marked, as 32 percent of male-authored papers adopt this paradigm compared to 19 percent female-authored papers.

Research Data. Female-authored papers have a slight tendency to use qualitative data more than male-authored papers, as 71 percent of male-authored papers use qualitative data compared to 78 percent female-authored papers. Similarly, maleauthored papers have a tendency to use quantitative data more than female-authored papers, as 13 percent of male-authored papers use quantitative data compared to 7 percent female-authored papers. 

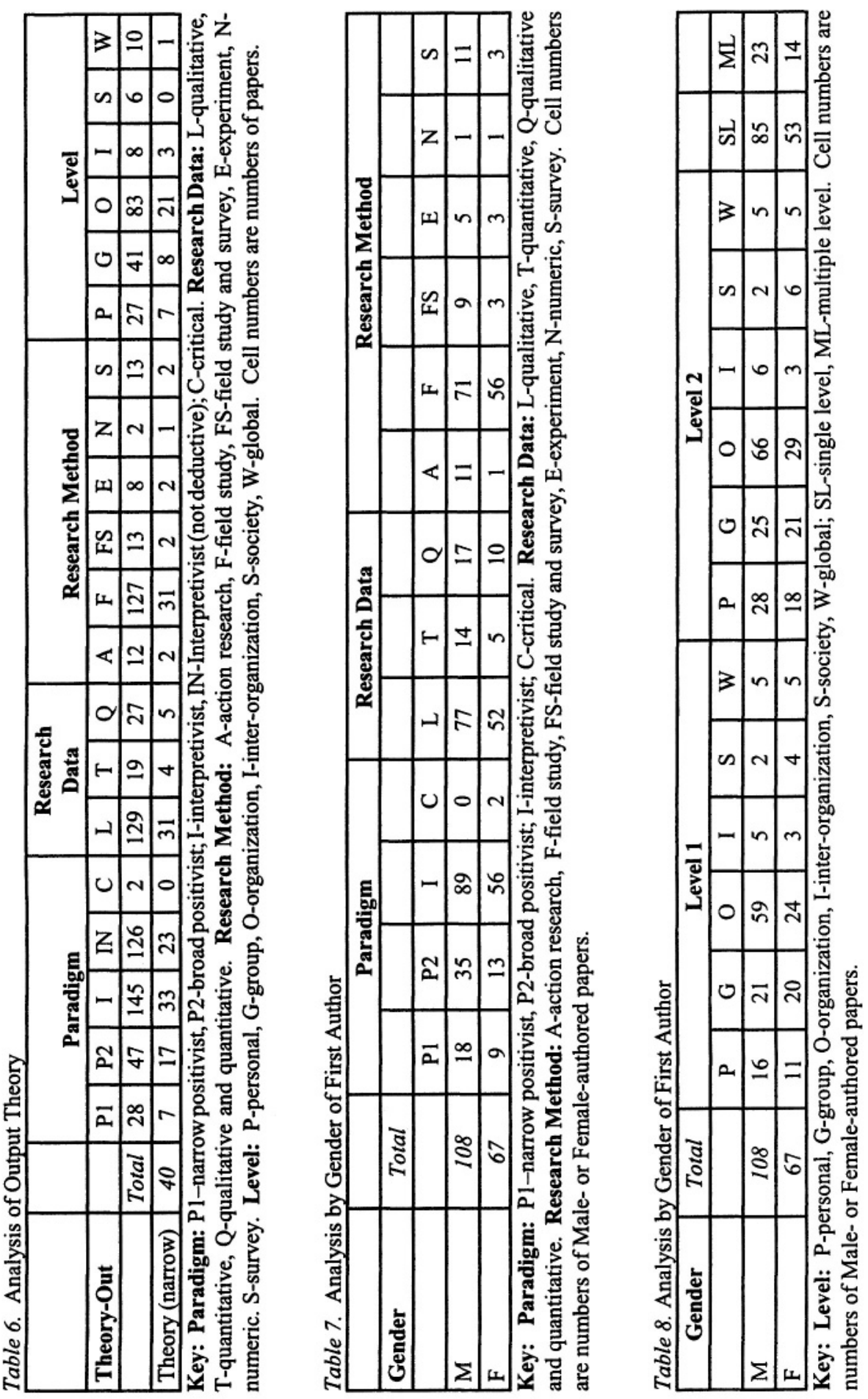
Research Method. We found it interesting that male-authored papers (10 percent) use the action research method much more than female-authored (1 percent) papers. This might be due to the fact that most action research takes place in organizations, typically run by men, and that female researchers may find that this culture is not conducive to such research. Female-authored papers use the survey method ( 3 percent) less than male-authored papers (11 percent). The great majority ( 84 percent) of femaleauthored papers use the field study method compared to male papers (66 percent).

Level. The level 1 figures in Table 8 refer to those papers which focus on only one level or, for papers that focus on more than one level, where we have made a decision as to the primary level on which they focus. The level 2 figures refer to all of the levels on which papers focus.

Female-authored papers (43 percent) focus on the organizational level much less than male-authored papers (61 percent), but focus more on the group level (31 percent female-authored papers compared to 23 percent male-authored papers), and the society level ( 9 percent female-authored papers compared to 2 percent male-authored papers). About the same proportion (26 percent) of male-authored and female-authored papers focus on the personal level. With regard to focus on single or multiple levels, 21 percent of both male-authored and female-authored papers focus on multiple levels, with the personal and organization levels being the level of focus most frequent in multiple level papers.

Input theory. Female-authored papers have a different approach to the use of theory on input, as 13 percent use theory deductively with 67 percent using theory sensitizingly. In comparison, for male-authored papers, 22 percent use theory deductively with 60 percent using theory sensitizingly. Male-authored papers (40 percent), compared to female-authored papers ( 30 percent), have more of a tendency to use their own input theory. Of these male-authored papers, 47 percent test their theory, while of these female-authored papers, 35 percent test their theory.

Output theory. In all, 27 percent of male-authored papers and 16 percent of femaleauthored papers generate theory, according to our narrow definition in section 3.7 above. If we consider the wider definition, the difference is more marked, with 67 percent of male-authored papers and 46 percent of female-authored papers generating wide theory. Thus male-authored papers tend to generate their own theory more, compared to femaleauthored papers.

Region. Of the Australasian papers, there are more female-authored papers (59 percent) than male-authored, with 41 percent of papers from North America and 33 percent from Europe female-authored papers.

ISR category. We found that female-authored papers (43 percent) fall into the embedded ensemble category more than male-authored papers (35 percent); maleauthored papers also fall into the nominal, proxy, and tool categories more than femaleauthored papers.

\subsection{Region of First Author}

This section investigates the relationship between first author region and different categories of papers, shown in Tables 10, 11, and 12. 


Table 12. Analysis by Region of First Author

\begin{tabular}{|l|c|c|c|c|c|c|c|c|c|c|c|c|c|c|c|}
\hline Region & Total & \multicolumn{9}{|c|}{ Theory-In } & \multicolumn{7}{c|}{ Theory-Out } & \multicolumn{7}{|c|}{ ISR Category } \\
\hline & & D & S & I & OT & DOT & T1 & T2 & ED & EE & EP & ES & N & P & T \\
\hline AN & 59 & 15 & 33 & 11 & 26 & 12 & 16 & 38 & 18 & 21 & 3 & 0 & 3 & 2 & 12 \\
\hline AU & 17 & 3 & 9 & 5 & 3 & 2 & 3 & 5 & 8 & 6 & 1 & 0 & 1 & 0 & 1 \\
\hline EU & 93 & 14 & 67 & 12 & 34 & 12 & 18 & 39 & 41 & 38 & 5 & 2 & 2 & 2 & 3 \\
\hline
\end{tabular}

Key: Theory-In: D-deductive, S-sensitising, I-inductive; OT-own theory, DOT-deductive own theory. Theory-Out: T1-narrow theory, T2-wide theory. ISR Category: ED-ensemble development. EE-ensemble embedded, EP-ensemble production network, ES- ensemble structure; N-nominal; P-proxy; T-tool. Cell numbers are numbers of North American (AN), Australasian $(\mathrm{AU})$ or European (EU) papers.

Research paradigm. In all, 32 percent of North American papers adopt a narrow positivist paradigm. This proportion is significantly more than the 8 percent of European papers that are positivist. No Australasian papers are positivist from this view. On the broad view of positivist (including papers with a deductive use of theory), North American papers are again in the majority, increasing to 39 percent, European papers increase to 19 percent, while Australasian papers increase to 18 percent.

However, these results do not necessarily support the perception that North America continues to favor the positivist paradigm, as the majority of its positivist papers date from the late 1980s and early 1990s. In the last five years, the proportions of positivist papers (on both narrow and broad views) from North American and Europe are approximately equal.

Data. A higher proportion (81 percent) of European and Australasian papers use exclusively qualitative data, compared to 61 percent of North American papers. In contrast, 20 percent of North American papers use exclusively quantitative data, while Australasian papers do not use quantitative data exclusively at all. About the same proportion of all papers use mixed qualitative and quantitative data. However, following the trend of the positivist paradigm, although not to the same extent, more of the recent North American papers use qualitative data exclusively.

Research Method. In all, 75 percent of European and Australasian papers and 68 percent of North American papers use the field study method exclusively. A total of 10 percent of European papers use action research, compared to 3 percent and 6 percent respectively for North American or Australasian papers. Surveys are not used exclusively in Australasian papers. A total of 12 percent of North American papers use the experimental method, compared to no European papers.

Level. In all, 25 percent of European papers focus on more than one (typically two) levels; the most popular of these are organization-personal, group-personal and global-organization. In comparison, 18 percent and 15 percent of Australasian and North American papers respectively focus on more than one level. The primary focus of European (57 percent) and North American (41 percent) papers is on the organizational level. In contrast, the primary focus of Australasian papers is the group level. North American papers focus on the personal level more than other regions. The interorganizational, society, and global levels together account for only 13 percent of papers. 
Input theory. Sensitizing use of input theory is most popular for European papers. In contrast, a greater proportion of North American and Australasian papers use theory deductively and inductively. North American papers use theory deductively (25 percent) more than other regions, whereas Australasian papers use theory Inductively (29 percent) more than other regions.

The authors of North American papers (44 percent), compared to the authors of Australasian papers (18 percent), are more inclined to use their own input theory. Of the North American papers, 20 percent test their theory, while of the Australasian and European papers, 13 percent test their theory.

Output theory. There are some major differences between regions: measured widely, 64 percent of North American papers generate theory, compared to 42 percent of European and 29 percent of Australasian papers.

ISR category. In all, 72 percent of North American papers fall within the ISR embedded category, with 20 percent of papers in the proxy category. This is less than European and Australasian papers, where 92 percent and 88 percent respectively fit the embedded category.

\section{DISCUSSION AND CONCLUSIONS}

This review of the past 20 years of IFIP WG 8.2 conferences has found that empirical research has changed over the years in response to the dialogue within the community. One of the clearest changes over the period has been the move toward use of the interpretivist research paradigm and qualitative data. The debate over research paradigms that started at the 1984 conference was not a call to drop positivist research altogether but a call for a wider diversity in research. There were some doubts expressed at the 1984 conference about whether the community would allow this to happen. The need for legitimation of interpretivist research discussed by many authors (King and Applegate 1997) thus appears to have been achieved.

Relating our study to similar work, we found that our results were significantly at variance with those of Sawyer and Chen (2002). For the WG 8.2 papers surveyed, they found 29 percent of papers were in the ensemble category and 45 percent of papers were in the nominal category, compared to our results where 84 percent of the papers were in the ensemble category and 3 percent were in the nominal category. Although some of this variance can be accounted for by the fact that Sawyer and Chen included all papers from an 11-year period, whereas we included only about half from a 20-year period, the differences between the Sawyer and Chen and the Orlikowski and Iacono surveys indicate that there are clearly large differences between categorization of individual papers, possibly reflecting different views on the position of the sociotechnical boundary between IT as an artifact and its context.

Highlights of our results are

- In all, 83 percent of the papers adopt the interpretivist paradigm, 74 percent use qualitative data and 73 percent use field studies.

- The organization is the main level of focus (54 percent), followed by group (26 percent) and personal (26 percent). 
- In all, 63 percent of the papers use sensitizing theory, 19 percent deductive and 18 percent inductive.

- In all, 36 percent of the papers use authors' own input theory.

- In all, 22 percent of the papers generate theory.

- Contrary to expectation, we did not find that positivist papers, papers that used quantitative data, and survey papers were more likely to generate theory.

- Male-authored papers are more likely to be positivist, to generate theory and to focus on the organizational level.

- North American papers are more likely to generate theory and less likely to be qualitative.

We found that the top 10 social theories were only used by about a fifth of the papers, perhaps indicating that authors are casting their net widely when looking for theories to help them make sense of research settings. We were intrigued to find that our top 10 theories were similar to Jones' (2000) findings. This implies that researchers do not necessarily "spray" fashionable citations about in their work; on the contrary, if a theory is cited, it generally means it is deeply integrated into the research.

Jones concluded his paper by stating, "The question for IS researchers, therefore, is not whether they should engage with social theory, but how to do so." As we have found, on the narrow definition of theory, only 22 percent of papers generate theory or concepts, according to Walsham's (1995) classification. The impressions of the commentators cited in the introduction appear to be borne out by the evidence. Grunow (1995), quoted in Sawyer (2000), finds 82 percent of organizational research papers did not contribute to theory development.

However, in section 3.7 above, we introduced a wide definition of output theory that includes authors' own theory where it is used as input theory. Our reason for taking this view is that, in the 36 percent of papers that use authors' own theory as input theory, there are very few citations to previously published work for the theory. In this way, it appears that authors may in fact be generating theory, but in a non-explicit manner, by using it as sensitizing or deductive theory. On this wide definition, 49 percent of papers generate theory.

The majority of WG 8.2 researchers appear to be reluctant to generalize to theory or concepts from their findings, particularly when undertaking interpretivist research. However, Baskerville and Lee (1999) point out that IS researchers are unnecessarily handicapping themselves with well-meaning but scientifically inaccurate conceptions of the conditions under which generalization may be claimed, and proceed to give clear examples of how progress in this area may be made. Taken together with our finding that, according to our wide definition of theory, theory is being generated in papers in a non-explicit manner, there thus appears to be room in the future for WG 8.2 researchers to familiarize themselves with the view that there are forms of generality that are possible within the interpretivist paradigm. If they can be convinced of its possibilities, they can make theory more explicit and can further the theory development aspect of their work toward generalization, with its benefits of portability of results between research studies, relevance for practitioners, and possible contribution from the IS discipline to other disciplines. 
Concerning the process of paper categorization in which we have been engaged, our experience is that this has been a learning process whereby the meaning and application of our categories has iteratively emerged from several readings of the papers, our studies of IS research methodology literature, discussions, conceptualizations, and (re)definitions. Our understanding of some of the categories changed over the duration of this process. From the categorization discussion earlier we indicated that, for some categories and subcategory boundaries, we had difficulty in constructing definitions about which we could agree. From our experience in writing this paper, we recommend paper categorization of a substantial body of IS research as a good approach to questioning and clarifying our basic concepts.

\section{REFERENCES}

Alvesson, M., and Skoldberg, K. Reflexive Methodology, London: Sage Publications, 2000. Avison, D.; Kendall, J. E.; and DeGross, J. I. (Eds.). Human, Organizational, and Social Dimensions of Information Systems Development, Amsterdam: North-Holland, 1993.

Baskerville, R., and Lee, A. S. "Distinctions Among Different Types of Generalizing in Information Systems Research," in O. Ngwenyama, L. D. Introna, M. D. Myers, and J. I. DeGross (Eds.), New Information Technologies in Organizational Processes: Field Studies and Theoretical Reflections on the Future of Work, Boston: Kluwer Academic Publishers, 1999, pp. 49-65.

Baskerville, R.; Ngwenyama, O.; Smithson, S.; and DeGross, J. I. (Eds.). Transforming Organizations with Information Technology, Amsterdam: North-Holland, 1994.

Baskerville, R.; Stage, J.; and DeGross, J. I. (Eds.). Organizational and Social Perspectives on Information Technology, Boston: Kluwer Academic Publishers, 2000.

Baskerville, R., and Wood-Harper, A. T. "A Critical Perspective on Action Research as a Method for Information Systems Research,” Journal of Information Technology (11), 1996, pp. 235246.

Bjørn-Andersen, N., and Davis, G. B. (Eds.). Information Systems Assessment: Issues and Challenges, Amsterdam: North-Holland, 1988.

Brinkkemper, S.; Lyytinen, K.; and Welke, R. J. (Eds.). Method Engineering: Principles of Method Construction and Tool Support, London: Chapman \& Hall, 1996.

Bryman, A. Social Research Methods, Oxford: Oxford University Press, 2001.

Eisenhardt, K. M. "Building Theories from Case Study Research," Academy of Management Review (14:4), 1989, pp. 532-550.

Grunow, D. “The Research Design in Organization Studies,” Organization Science (6:1), 1995, pp. 93-103.

Hirschheim, R., and Klein, H. K. "Information Systems Research at the Crossroads: External Versus Internal Views,” in R. Baskerville, J. Stage, and J. I. DeGross (Eds.), Organizational and Social Perspectives on Information Technology, Boston: Kluwer Academic Publishers, 2000, pp. 233-254.

Jones, M. "The Moving Finger: The Use of Social Theory in WG 8.2 Conference Papers, 19751999," in R. Baskerville, J. Stage, and J. I. DeGross (Eds.). Organizational and Social Perspectives on Information Technology, Boston: Kluwer Academic Publishers, 2000, pp. 1532.

Kaiser, K. M., and Oppeland, H. J. (Eds.). Desktop Information Technology, Amsterdam: North Holland, 1990.

Kendall, K. E.; Lyytinen, K.; and DeGross, J. I. (Eds.). The Impact of Computer Supported Technologies on Information Systems Development, Amsterdam: North-Holland, 1992. 
King, J. L., and Applegate, L. M. "Crisis in the Case Study Crisis: Marginal Diminishing Returns to Scale in the Quantitative-Qualitative Research Debate," in A. S. Lee, J. Liebenau, and J. I. DeGross (Eds.), Information Systems and Qualitative Research. London: Chapman \&Hall, 1997, pp. 28-30.

Klein, H. K. "Knowledge and Methods in IS Research: from Beginnings to the Future," in O. Ngwenyama, L. D. Introna, M. D. Myers, and J. I. DeGross (Eds.), New Information Technologies in Organizational Processes: Field Studies and Theoretical Reflections on the Future of Work, Boston: Kluwer Academic Publishers, 1999, pp. 13-25.

Klein, H. K., and Huynh, M. Q. "The Potential of the Language Action Perspective in Ethnographic Analysis," in O. Ngwenyama, L. D. Introna, M. D. Myers, and J. I. DeGross (Eds.), New Information Technologies in Organizational Processes: Field Studies and Theoretical Reflections on the Future of Work, Boston: Kluwer Academic Publishers, 1999, pp. 79-95.

Klein, H. K., and Kumar, K. (Eds.). Systems Development for Human Progress, Amsterdam: North-Holland, 1989.

Korpela, M., Montealegre, R., and Poulymenakou, A. (Eds.). Organizational Information Systems in the Context of Globalization, Boston: Kluwer Academic Publishers, 2003.

Larsen, T. J., Levine, L., and DeGross, J. I. (Eds.). Information Systems: Current Issues and Future Challenges, Laxenburg, Austria: IFIP, 1998.

Lee, A. S., Liebenau, J, and DeGross, J. I. (Eds.). Information Systems and Qualitative Research, London: Chapman \& Hall, 1997.

Mumford, E., Hirschheim, R., Fitzgerald, G., and Wood-Harper, T. (Eds.). Research Methods in Information Systems, Amsterdam: North-Holland, 1985.

Myers, M. D. "ISWorld: Qualitative Research in Information Systems" (available online at www.qual.auckland.ac.nz/; last accessed 24 January 2004).

Ngwenyama, O., Introna, L. D., Myers, M. D., and DeGross, J. I. (eds). New Information Technologies in Organizational Processes: Field Studies and Theoretical Reflections on the Future of Work, Boston: Kluwer Academic Publishers, Kluwer, 1999.

Nissen, H-E., Klein, H. K., and Hirschheim, R. (Eds.). Information Systems Research: Contemporary Approaches and Emergent Traditions, Amsterdam: North-Holland, 1991.

Orlikowski, W. J., and Iacono, C. S. "Research Commentary: Desperately Seeking the 'IT' in IT Research-A Call to Theorizing the IT Artifact," Information Systems Research (12:2), June 2001, pp. 121-134.

Orlikowski, W. J., Walsham, G., Jones, M. R., and DeGross, J. I. (Eds.). Information Technology and Changes in Organizational Work, London: Chapman \& Hall, 1996.

Russo, N. L., Fitzgerald, B., and DeGross, J. I. (Eds.). Realigning Research and Practice in Information Systems Development: The Social and Organizational Perspective, Boston: Kluwer Academic Publishers, 2001.

Sawyer, S. "Studying Organizational Computing Infrastructures: Multi-Method Approaches," in R. Baskerville, J. Stage, and J. I. DeGross (Eds.), Organizational andSocial Perspectives on Information Technology, Boston: Kluwer Academic Publishers, 2000, pp. 213-231.

Sawyer, S., and Chen, T. T. "Conceptualizing Information Technology in the Study of Information Systems," in E. H. Wynn, E. A. Whitley, M. D. Myers, and J. I. DeGross (Eds.). Global and Organizational Discourse about Information Technology, Boston: Kluwer Academic Publishers, 2002, pp. 109-131.

Silverman, D. Doing Qualitative Research: A Practical Handbook, London: Sage Publications, 2000.

Van Maanen, J. "Fear and Loathing in Organizational Studies," Organization Science (6:6), 1995, pp. 687-692.

Walsham, G. "Globalization and IT: Agenda for Research," in R. Baskerville, J. Stage, and J. I. DeGross (Eds.), Organizational and Social Perspectives on Information Technology, Boston: Kluwer Academic Publishers, 2000, pp. 195-210. 
Walsham, G. "Interpretive Case Studies in IS Research: Nature and Method,” European Journal of Information Systems (4:2), June 1995, pp. 74-81.

Wynn, E. H., Whitley, E. A., Myers, M. D., and DeGross, J. I. (Eds.). Global and Organizational Discourse about Information Technology, Boston: Kluwer Academic Publishers, 2002.

\section{ABOUT THE AUTHORS}

Donal Flynn has 11 years experience in the UK, Netherlands, and Belgium as programmer, database designer, project consultant and project manager. He has degrees in Chemical Physics (B.Sc., University of Kent), Sociology and Psychology (M.Sc., Imperial College, University of London) and Conceptual Modeling (Ph.D., University ofEast Anglia). His research interests are in the socio-organizational processes that underlie the interaction between IT systems and their human and organizational contexts. He is currently a senior lecturer in Information Systems at the Department of Computation, University of Manchester Institute of Science and Technology. He can be reached at donal.flynn@umist.ac.uk.

Peggy Gregory is currently a senior lecturer in Computing at the University of Central Lancashire, UK. She has been working in academic computing for the past 10 years, having previously worked in the business sector as a programmer and IT Manager. She has degrees in Theology (B.A., University of Bristol) and Software Development (M.Sc., University of Huddersfield). Her research interests are in the development and use of information systems in their organizational context.

\section{Appendix A}

\section{Papers and Their Categorizations}

\begin{tabular}{cl}
\hline Year & \multicolumn{1}{c}{ Categorized Papers } \\
\hline 1986 & Davis/Srinivasan, M, I, QL, F, O, 1, A, T, EE, AN; Robey, M, I, QQ, F, G, 2, A, S, \\
& ED, AN; Sandstrom, F, I, QQ, F, G, 2, B, R, EE, EU; Davis/Hamann, M, I, QQ, A, \\
& O, 2, A, R, EE, AN; Etzerodt, M, I, QL, F, PG, 3, , R, EE, EU; Blackler, M, I, QL, F, \\
& O, 2, B, S, EE, EU; Lange, M, P, QQ, FS, O, 1, A, T, TS, EU \\
\hline 1987 & Ciborra, M, I, QL, F, O, 2, A, R, ED, EU; Gurstein, M, I, QL, F, PO, 2, B, S, ED, \\
& AN; Kendall, M, P, QQ, F, G, 2, B, C, ED, AN; Hellman, F, I, QL, F, G, 1, B, S, \\
& ED.EU \\
\hline 1989 & Kling, M, I, QQ, FS, G, 2, A, S, EE, AN; Seror, F, I, QQ, F, P, 2, B, R, EE, AN; \\
& Gogan, F, I, QL, F, O, 3, , T, PP, AN; Brown, F, P, QQ, FS, O, 1, B, R, PD, AN; \\
& Yap, F, P, QT, S, P, 3, , S, PP, AA; Klepper, M, P, QQ, FS, O, 1, A, R, PD, AN; \\
& Olfman, M, P, QT, E, P, 1, A, T, PP, AN; George, M, P, QT, FS, G, 2, B, R, EE, \\
& AN; Sein, M, P, QT, E, P, 2, A, S, PP, AN; Frank, M, P, QT, S, P, 1, A, S, PP, AN; \\
& Carlsson, M, I, QL, F, P, 2, A, S, EE, EU; Webster, F, P, QT, E, P, 1, A, S, EE, AN; \\
& Lin, M, P, QT, E, P, 1, B, S, TS, AN \\
\hline 1990 & Elam, F, P, QQ, F, G, 2, B, R, ED, AN; Cooper, M, P, QT, N, O, 1, A, S, PC, AN; \\
Banville, M, I, QL, F, O, 2, B, R, EE, AN; Davies, F, I, QL, F, O, 2, A, R, N, AU; \\
Calloway, F, I, QL, E, G, 3, , R, ED, AN; Toraskar, M, I, QL, F, P, 3, , T, EE, AN; \\
Lee/Goldstein, M, P, QT, S, G, 2, A, S, N, AN; Baskerville, M, I, QL, E, P, 2, A, R, \\
ED, AN
\end{tabular}




\section{Year Categorized Papers}

1992 Wynekoop, F, P, QT, S, P, 1, A, R, PP, AN; Sumner, F, P, QQ, F, O, 3, , R, PD, AN; Aaen, M, I, QT, S, OW, 3, , R, PD, EU; Becker, F, P, QT, E, G, 2, A, R, ED, AN; Wanninger, M, I, QL, F, G, 1, A, S, ED, AN; Vician, F, P, QQ, F, G, 1, A, R, PP, AN; Davies, F, I, QL, F, G, 3, , R, ED, AU; Jones, M, I, QL, F, G, 2, B, R, ED, EU; Baskerville, M, I, QL, A, OG, 2, B, R, ED, AN

1993 Willcocks, M, P, QT, S, O, 3, , S, P, EU; Millett, M, P, QQ, SF, O, 2, A, S, P, EU; Kaasboll, M, IP, QQ, SF, P, 2, A, S, ED, EU; Frietas, M, P, QT, S, P, 2, B, T, TI, AS; Goldkuhl, M, I, QL, A, G, 2, A, S, ED, EU; Morley, F, I, QL, A, P, 3, , T, ED, EU; Guimares, M, P, QT, F, P, 1, A, T, PP, AN; Trauth, F, I, QL, F, S, 2, A, R, EP, AN; Fitzgerald, M, I, QQ, SF, O, 3, , R, ED, EU; Parkin, M, I, QL, F, O, 1, B, T, PD, AU; Heiskanen, M, I, QL, A, O, 2, B, R, ED, EU; Fischer, M, I, QL, F, O, 2, B, S, EE, EU; Little, M, I, QL, F, O, 3, , S, ED, AU; Ledington, M, I, QL, A, G, 1, A, S, ED, AU; Jones, M, I, QL, F, PO, 2, B, R, ES, EU

1994 Applegate, F, I, QL, F, O, 2, A, T, EE, AN; Ciborra, M, I, QL, F, O, 2, B, C, N, EU; Willcocks, M, I, QQ, SF, O, 2, B, T, EE, EU; Janson, M, I, QL, F, O, 1, B, R, N, AN; Hales, M, I, QL, F, OG, 2, A, T, ED, EU; Korpela, F, I, QL, F, OG, 2, B, S, ED, EU; Davies, F, I, QL, F, G, 2, B, S, ED, AU; Douzou, F, I, QL, F, G, 2, B, R, EE, AN; Mumford, F, I, QL, F, G, 2, A, R, ED, EU; Wilson, M, I, QL, F, O, 2, B, R, EE, EU; Jones, M, I, QL, F, O, 2, B, R, EE, EU; Bjorn-Andersen, M, I, QL, F, O, 2, B, C, EE, EU; Qureshi, F, I, QL, F, I, 2, B, S, EE, EU; Zimmerman, M, I, QL, F, PO, 3, R, EE, AN; Nance, M, I, QL, F, O, 2, B, R, T, AN

1995 Louw, F, I, QL, F, O, 2, A, R, ED, EU; Grint, M, I, QQ, FS, O, 2, B, R, EE, EU; Hamilton, M, I, QL, F, O, 2, B, R, ED, AU; Gallivan, M, I, QL, F, G, 2, B, T, ED, AN; Guimaraes, M, P, QT, S, P, 1, A, S, EE, AN; Scarbrough, M, I, QL, F, O, 2, A, S, ED, EU; Gasson, F, I, QQ, S, O, 1, A, S, ED, EU; Vidgen, M, I, QL, F, O, 2, B, R, EP, EU; Monteiro, M, I, QL, F, O, 2, B, R, EE, EU; Bowker, M, I, QL, F, O, 2, A, R, ED, AN; Bloomfield, M, I, QL, F, P, 2, B, R, EE, EU; Ciborra, M, I, QL, F, O, 2, A, R, EE, EU

1996 Van Slooten, M, I, QQ, F, G, 1, A, R, ED, EU; Mathiassen, M, I, QL, F, G, 2, B, R, ED, EU; Peters, M, P, QQ, F, G, 1, A, R, TI, EU

1997 Urquhart, F, I, QL, F, P, 3, , T, ED, AU; Janson, M, I, QL, F, PO, 3, , R, N, AN; Mantelaers, M, I, QL, F, PG, 3, , R, ED, EU; Sawyer, M, I, QL, F, PO, 2, A, R, EE, AN; Romm, F, I, QQ, F, PO, 2, B, R, EE, AU; Silva, M, I, QL, F, O, 2, A, R, EE, EU

1998 Howcroft, F, I, QL, F, P, 2, A, T, EE, EU; Riva, M, I, QL, F, O, 1, A, T, ED, EU; Aaen, M, I, QL, A, O, 1, A, T, ED, EU; Iversen, M, I, QL, A, O, 2, B, S, ED, EU; Harvey, F, I, QL, F, O, 2, B, R, EE, AU; Baskerville, M, I, QL, F, O, 3, , T, ED, AN; Seppanen, M, I, QL, F, I, 2, A, S, ED, EU; Monteiro, M, I, QL, F, O, 2, B, R, EE, EU; Gasson, F, I, QL, F, G, 2, B, T, ED, AN; Kaplan, F, I, QL, F, O, 2, B, R, EE, AN; Urquhart, F, I, QL, F, P, 3, , S, ED, AU; Levy. F, I, QL, F, O, 2, A, R, EE, EU; Butler, M, I, QL, F, O, 2, B, R, EE, EU; Damsgaard, M, I, QL, F, IW, 2, A, R, EE, EU; Leist, F, P, QT, N, O, 1, A, T, ED, EU; Heiskanen, M, I, QL, F, I, 2, A, R, ED, EU; Brooke, F, I, QL, F, G, 1, A, R, ED, EU; Kirveennummi, M, I, QL, F, O, 2, A, R, EE, EU; Kautz, M, I, QQ, S, PO, 3, , S, EE, EU

1999 Sauer, M, I, QL, F, I, 3, , S, EE, AU; O’Donovan, M, I, QL, F, O, 1, A, T, EE, AF; Scheepers, M, I, QL, F, O, 2, B, R, ED, EU; Sarker, M, I, QL, F, 0, 3, , T, ED, AN; Karsten, F, I, QL, F, G, 2, B, R, ED, EU; Spitler, F, I, QL, F, G, 2, B, T, EE, AN 


\begin{tabular}{|c|c|}
\hline Year & Categorized Papers \\
\hline 2000 & $\begin{array}{l}\text { Braa, F, I, QL, F, O, 2, A, C, ED, EU; Crowston, M, I, QL, F, PO, 2, A, S, ED, AN; } \\
\text { Lamb, F, I, QL, F, O, 2, B, R, EE, AN; Pouloudi, F, I, QL, F, O, 2, B, R, ED, EU; } \\
\text { Aanestad, F, I, QL, F, O, 2, B, R, EE, EU; Mark, F, I, QL, F, G, 2, A, R, EE, AN; } \\
\text { Grunden, F, I, QL, F, O, 1, A, S, ED, EU; Karsten, F, I, QL, F, G, 2, A, S, EE, EU; } \\
\text { Wilson, F, I, QL, F, PO, 2, B, S, EE, EU; Eriksen, M, I, QL, A, G, 1, B, R, ED, EU }\end{array}$ \\
\hline 2001 & $\begin{array}{l}\text { Baskerville/Stage, M, I, QL, F, G, 1, A, T, ED, AN; Baskerville/Pries-Heje, M, I, } \\
\text { QL, F, OG, 3, , T, ED, AN; Hedstrom, F, I, QL, F, P, 3, , S, ED, EU; Lang, M, P, } \\
\text { QT, S, O, 3, , S, ED, EU; Moreton, M, I, QL, F, O, 1, A, T, ED, EU; Nandhakumar, } \\
\text { M, I, QL, F, POG, 2, B, R, EP, EU; Allen, M, I, QL, F, O, 3, , R, EE, EU; } \\
\text { Eschenfelder, F, I, QL, F, O, 2, B, R, ED, AN; Henfridsson, M, I, QL, A, O, 2, B, R, } \\
\text { ED, EU; Brooks, M, P, QT, S, P, 3, , S, EE, EU; Rehbinder, M, I, QL, F, PG, 1, A, } \\
\text { T, ED, EU; Nielsen, M, I, QL, A, O, 2, B, S, ED, EU; Rose, M, I, QL, A, G, 2, B, S, } \\
\text { ED, EU; Bonner, M, I, QL, F, PS, 2, B, R, EP, AN }\end{array}$ \\
\hline 2002 & $\begin{array}{l}\text { Lamb, F, I, QL, F, O, 3, , C, EE, AN; Edenius, M, I, QL, F, P, 2, B, R, EE, EU; } \\
\text { Wastell, M, I, QL, F, O, 2, B, R, EE, EU; Wilson, F, C, QL, F, PO, 2, B, R, EE, EU; } \\
\text { Monod, M, I, QL, F, O, 2, B, R, N, EU; Kvasny, F, C, QL, F, PG, 2, A, R, EE, AN; } \\
\text { Metcalfe , M, I, QL, E, G, 1, A, T, ED, AU; Atkinson, M, I, QL, F, G, 1, A, T, ED, } \\
\text { EU; Abbot, F, I, QL, F, OW, 2, B, R, EP, EU; Wagner, F, I, QL, F, P, 2, B, R, EE, } \\
\text { AN; Rose, M, I, QL, F, PO, 2, B, T, ES, EU; Ellingsen, M, I, QL, F, PO, 2, B, R, } \\
\text { EE, EU; McGrath, F, I, QL, F, PO, 2, B, R, EE, EU }\end{array}$ \\
\hline 2003 & $\begin{array}{l}\text { Firth, F, I, QL, F, G, 2, B, S, EE, AU; Hasan, F, I, QL, F, G, 2, B, R, EE, AU; Jutla, } \\
\text { F, I, QL, F, O, 2, A, R, EE, AN; Okunoye, M, I, QQ, F, OW, 2, A, T, EE, EU; } \\
\text { Samiotis, M, I, QL, F, O, 2, B, T, EE, EU; Chilundo, M, I, QL, F, SO, 3, , R, EE, } \\
\text { AF; Joham, F, I, QQ, SF, SW, 3, , S, EP, AU; Kopanaki , F, I, QL, F, I, 2, B, T, EE, } \\
\text { EU; Seror, F, I, QL, F, S, 3, , R, EP, AN; Stein, M, I, QQ, SF, OW, 2, B, R, EE, AU; } \\
\text { Abbot, F, I, QL, F, OW, 2, B, R, EP, EU; D’Mello, F, I, QL, F, POW, 2, B, R, EP, } \\
\text { EU; Kiely, F, I, QL, F, O, 3, , R, ED, EU; Mursu, F, I, QQ, SF, SO, 2, B, R, ED, EU; } \\
\text { Nicholson, M, I, QL, F, OW, 2, B, R, ED, EU; Sharma, M, I, QL, F, I, 3, , T, ED, } \\
\text { AA; Byrne, F, I, QL, F, PG, 2, B, S, ED, AF; Madon, F, I, QL, F, PS, 2, B, R, EE, } \\
\text { EU; Prasopoulou, F, I, QL, F, I, 2, B, R, EE, EU; Jaghoub, F, I, QL, F, SW, 2, B, R, } \\
\text { EE, EU; Meso, M, P, QQ, S, I, 2, B, T, PD, AN }\end{array}$ \\
\hline
\end{tabular}

Data categories listed in order after first author name: Gender $-\mathrm{M}=$ Male, F = Female; Research Paradigm $-\mathrm{I}=$ Interpretivist, $\mathrm{P}=$ Positivist, $\mathrm{C}=$ Critical; Research Data $-\mathrm{QL}=$ Qualitative, QT = Quantitative, $\mathrm{QQ}=$ Mixed Qualitative and Quantitative; Research Method $-\mathrm{F}=$ Field study, $\mathrm{S}=$ Survey, FS = Field study \& Survey, E = Experiment, $\mathrm{A}=$ Action Research, $\mathrm{N}=$ Numerical methods; Level $-\mathrm{W}=$ Global, $\mathrm{S}=$ Social, $\mathrm{I}=$ Interorganisational, $\mathrm{O}=$ Organizational, $\mathrm{G}=$ Group, $\mathrm{P}=$ Personal; Input Theory - 1 = Deductive, 2 = Sensitizing, 3 = Inductive; Own/Other Theory - A = Author's own, B = Another author; Output Theory $-\mathrm{T}=$ Theory, $\mathrm{C}=$ Concepts, R = Rich Insights, $\mathrm{S}=$ Specific Implications; ISR Category $-\mathrm{T}=\mathrm{Tool}(\mathrm{TL}=$ labor substitution, $\mathrm{TP}=$ productivity, $\mathrm{TI}=$ information processing, $\mathrm{TS}=$ social relations $), \mathrm{P}=$ Proxy $(\mathrm{PP}=$ perception, $\mathrm{PD}=$ diffusion, $\mathrm{PC}=$ capital $), \mathrm{E}=$ Ensemble $(\mathrm{ED}=$ development project, $\mathrm{EP}=$ production network, $\mathrm{EE}=$ embedded system, $\mathrm{ES}=$ structure), $\mathrm{N}=$ Nominal Region $-\mathrm{AA}=\mathrm{Asia}$, $\mathrm{AF}=$ Africa, $\mathrm{AN}=$ North America, $\mathrm{AS}=$ South America, $\mathrm{AU}=$ Australasia, $\mathrm{EU}=$ Europe 